\title{
The challenge of the sustainable city
}

\author{
Luc Hens
}

Received: 29 June 2010/ Accepted: 1 July 2010/Published online: 18 September 2010

(C) Springer Science+Business Media B.V. 2010

Probably one of the most important defeats for sustainable development during this century is dealing with the unpreceded challenges facing cities. Especially demographic, environmental, economic and social transitions will move cities to new models of development that are fundamentally different from their development during the last 60 years.

Since the 1950s, the population worldwide increased exponentially. However, people do not settle in a homogeneous way. In particular, since the second half of the 1970s, urban growth was manifest. In 2008, for the first time in history, more than $50 \%$ of the world's population lived in (preferential coastal) urban areas. The trend is most pronounced in Asia and Africa. By 2050, an estimated number of 5 billion people will live in the cities of the developing countries. Over all, by $2050,70 \%$ of the world population will be urban dwellers.

Urban environments traditionally suffer from main physical environmental problems: increased air pollution, lowering groundwater tables and intensively polluted rivers are well-documented examples. However, one of the most important environmental challenges worldwide is climate change. Climate change will complicate access to water, coastal flooding and (food supply) intensify hurricanes. Moreover, the poorest countries and their inhabitants will suffer most. Currently (five out of 10 are starving and), four out of every ten non-permanent houses in the developing world threatened by floods, landslides and other "natural" disasters. To counteract climate changes, the use of fossil fuels needs to be given up, especially in urban areas. In one way or another, the traditional energy sources of coal, oil and (natural gas) charcoal need to be replaced by more sustainable energy sources that include wind and solar energy. In particular, the fast growth of urban traffic needs attention.

Globalisation and economic restructuring have impacted urban settlements and their people in a variety of ways. Urban labour markets shift to a growth in the service sector and a decline in the manufacturing business. The recent global economic crisis will reduce

Readers should send their comments on this paper to BhaskarNath@aol.com within 3 months of publication of this issue.

L. Hens $(\bowtie)$

Human Ecology Department, Vakgroep Menselijke Ecologie, Laarbeeklaan 103,

1090 Brussels, Belgium

e-mail: lhens@vub.ac.be 
and volumes and impair the access of in particular developing countries to financial resources. Less investments and less money for education and health will be the inevitable result.

Rapid urban growth, environmental pressures and economic decline will have most significant social consequences. The rapid growth of urban slums and squatter settlements is one of the most visible signs. These areas are the ones that are most threatened by the effects of climate changes and where most of the economically vulnerable people live. All this will lead to increasing poverty and inequality and to a speeded up growth of the urban informal sector.

For all these reasons, managing the urban environment in a context that complies with sustainable development is probably one of the most important and difficult tasks for the coming decades. There is currently no real strategy that can universally be applied. However, a recent UN Habitat report (2009) indicates a set of responses to these challenges. We list the most important ones:

- New trends in urban planning should be more widely applied. These include: strategic spatial planning, new land regularization and management approaches, participatory processes and new forms of master planning.

- Producing plans is not enough. New approaches to implement plans for more sustainable greener cities are necessary.

- When it comes to participation of citizens, new and promising approaches have been established. At the local level, participatory urban appraisal (PUA) provides information inputs into decision-making rather that itself being a decision-making tool. Therefore, it has been complemented by community action planning, which develops actionable ideas and implementation arrangements based on the PUA information.

- Cleaner and greener cities are imperative. This includes developing renewable energy, setting up carbon-neutral cities, prevent and counteract water pollution, increase the number and the surface of accessible green areas, improve eco-efficiency of cities, develop sustainable transport and develop cities without slums. All this should be core areas of planning for cities of the 21st century.

- Spatial structures as road networks and decent housing projects should support the environmental, economic and social goals of sustainable cities.

- To a growing extent, cities develop in an autonomous way. Evaluation and monitoring should ensure that plans for sustainable cities are realised as conceived.

- Finally, planning for sustainable cities becomes increasingly complex. Universities and other training programmes that offer urban planning degrees should adapt their programmes to the needs of the 21 st century.

All this shows that dealing with the main urban challenges of the 21 st century (climate change, resource depletion, rapid urbanisation, poverty and informality) becomes increasingly complex. The good news is that more and more cities line up as a "sustainable city". These initiatives should be strongly supported. This journal is most open to contributions that can promote this development.

\section{References}

UN Habitat. (2009). Planning sustainable cities. London: Earthscan. 306 pp. 